\title{
Protection Coordination of Distribution Network with Optimally Placed Distribution Generation
}

\author{
Abdullahi Bala Kunya*, Patrick Ubeh Okorie, Adamu Abubakar, Yusuf Jibril \\ Department of Electrical Engineering, Ahmadu Bello University, Zaria - Nigeria.
}

*Corresponding author: patrickubeokorie@ yahoo.com , Tel: +2348063244127.

\begin{abstract}
In this study, optimal distribution network protection coordination scheme with directional over current relays is developed. In addition, impact of optimally placed Distribution Generation (DG) on the protection coordination scheme is subsequently evaluated using relay Coordination Time Interval (CTI). As such, the study is carried out in two stages. In the first stage, optimal relays settings (time dial settings and pickup current) are determined. While in the second stage, the maximum DG penetration level with changes in the protection coordination is evaluated. Particle Swarm Optimization (PSO) algorithm, due to its faster convergence speed, is applied in both stages. The technique is implemented on the distribution section of the IEEE 14-bus and IEEE 30-bus systems and simulated in MATLAB. The simulation results obtained are compared with that obtained using hybrid Genetic Algorithm (GS) - Nonlinear Programming (NP) approach using relays pickup current and operating times as performance metrics. For the IEEE 14 bus system, the developed PSO-based relay coordination has reduced the relays pickup current and operating times by roughly $28 \%$ and $32 \%$ respectively compared with the hybrid GA-NLP technique. The optimal locations of the DGs are found to be bus 5, 8 and 12 which result in CTI of $0.233 \mathrm{sec}$. While in the IEEE 30 bus system, the developed relay coordination has reduced the relays pickup current and operating times by roughly $31 \%$ and $34 \%$ respectively compared with the hybrid GA-NLP technique. Similarly, the optimal locations and sizes of the DGs are found to be bus 19, 26 and 30, which result in CTI of $0.462 \mathrm{sec}$.
\end{abstract}

Keywords: directional over current relays, distribution generation, coordination time interval, time dial setting, pickupcurrent.

\section{INTRODUCTION}

The existing electrical distribution networks are constrained to accommodate limited amount of power from distributed generation (DG) sources. This is owing to the degradation of power quality resulting from the DG power injection, bidirectional power flow and deviations in voltage magnitudes and short circuit current levels. These consequences do not only affect the power quality but also alter the coordination of the protective devices [1]. The situation becomes more severe with the increase in the DG penetration level (PL) [2].

The main purpose of the protective devices in power system is to detect fault and isolate the selected faulty parts as quickly as possible to safeguard the system equipment and other auxiliaries [3, 4]. The most widely used form of protection in power system at sub-transmission and distribution level is over current protection relays (OCR). To improve the reliability of the protection mechanism, every relay in the power system is synchronized with another relays protecting the adjacent equipment. In the event of the first relay (known as primary relay) fails to respond due to occurrence of fault, then the second relay (regarded as backup relay) initiates its protection operation in a coordinated manner. In multi-source power systems like those with meshed and looped topologies, directional over current protection relays (DOCR) are most suitable choice for enhanced selectivity, since relays operate only when the fault current flows in the specific tripping direction desired $[5,6]$. In either case, the coordination of these protective devices is largely affected with the integration of DGs [7, 8]. It has been established that ssynchronous based DG has much more adverse effect on protection coordination than inverter based DGs.

Moreover, the most essential task when installing DOCR on the system is selecting their suitable pickup current and time settings such that their fundamental protective functions are met under the requirements of sensitivity, selectivity, reliability and speed. The coordination should be set in such a way that the relay that is closest to the fault (primary relay) operates as soon as possible and before all the adjacent relays (backup devices). Such a relay adjustment process tends to be a very complex task since the same relay can be the primary device in one situation 
and a backup device in another ones [5]. However, the problem of setting DOCR (optimal determination of the time dial settings (TDS) and pickup current, $I_{\mathrm{P}}$ ) is a highly constrained nonlinear optimization problem that has been solved using various heuristic and meta-heuristic techniques. For instance, invasive weed optimization is used in [9] to improve the overcurrent relay coordination performance. Coordination of distance and directional overcurrent relays using an extended continuous domain ant colony algorithm is presented in [2]. While in [10], a comparative analysis of various meta-heuristic optimization approaches for directional overcurrent relays coordination is presented. Similarly, [4] addressed OCR coordination using nonlinear programming combined with cuckoo search algorithm. The DOCR coordination based on constraint reduction and clustering is presented in [11]. While in [1], the DOCRs are optimally coordinated using Particle Swarm Optimization (PSO) technique. Instead of computing the TDS and $I_{\mathrm{P}}$ simultaneously, only the TDS is calculated while predefining the available $I_{\mathrm{P}}$ settings. In all these research works, less attention is paid to the impact of DG penetration to the DOCRs coordination.

Due to the increase in the integration of DG and the recent drive towards smart-grids, distribution systems are expected to be more of the meshed structure. This is why [12] and [13] proposed a protection coordination index (PCI) using a hybrid genetic algorithm (GA) - nonlinear programming (NLP) to quantify the impact of DG on protection coordination of DOCRs for looped distribution systems. The index can be utilized as a guiding tool while planning the protection of the meshed distribution system with DG. In spite of the demonstrated ability of the hybrid GA-NLP technique, meta-heuristic are generally known to have weak exploitation compared with deterministic approaches. On the other side, deterministic methods are not suitable for finding global optimum in a non-convex problems (leads to weak exploration). In addition, NLP approaches are susceptible to trapping into local minima/maxima.

Hence in this study, optimal distribution network protection coordination scheme with DOCRs is developed using an algorithm known for its faster convergence speed, Particle Swarm Optimization (PSO). In addition, impact of optimally placed DGs on the protection coordination scheme is subsequently evaluated using relay Coordination Time Interval (CTI). The significant contribution of this study are itemized as:-

$i$ - Developing the optimal distribution network protection coordination scheme with DOCRs using PSO.

ii- Determining the optimal location and size of the DGs while maximizing their penetration level.

iii-Evaluating the impact of the DGs on the protection coordination scheme using CTI.

The remainder of the paper is organized as follows. Particle swarm optimization is concisely reviewed in Section 2. In addition, the proposed protection coordination is discussed in Section 3 while the test systems used are described in Section 4.
Section 6 presents the tests, results and discussion and the paper is concluded in Section 6.

\section{PARTICLE SWARM OPTIMIZATION}

Particle swarm optimization (PSO) is a population based method that inspired from the behavior of the birds or fish (called particles represented by dimensional vectors) in a swarm. In the search space, each particle moves with a velocity as expressed in (1).

$$
V_{i}^{k+1}=\omega V_{i}^{k}+C_{1} r_{1}\left(p_{\text {best }}-X_{i}^{k}\right)+C_{2} r_{2}\left(g_{\text {best }}-X_{i}^{k}\right)
$$

where: $V_{i}^{t}$ is the velocity of particle $i$ at iteration $t, \omega$ is a weighting function, $C_{1}, C_{2}$ are constants cognitive and social weighing parameters respectively, $r_{1}$ and $r_{2}$ are two uniform random numbers between zero and one, $p_{\text {best }}$ is the best solution of the particle $i, g_{\text {best }}$ is the best solution in the swarm. The particle adapts this velocity due to the information exchange with other neighbors. At each iteration, the particle uses a memory in order to save its best position and the overall best particle positions. The best particle position is saved as a best position, which was assigned to a neighborhood particles in the swarm. The new position is then updated using (2):

$$
X_{i}^{k=1}=X_{i}^{k}+V_{i}^{k+1}
$$

Details about the underlying concept behind PSO formulation can be found in $[14,15]$.

\section{PROPOSED PROTECTION COORDINATION AND DG IMPACT EVALUATION}

For a typical fault, each backup relay operates subsequent to its primary relays and particularly, subsequent to the primary relay with the largest operating time after an elapsed coordination time interval (CTI) time difference. However, setting the operation time difference between the primary and backup relays equal to CTI, especially in meshed networks (bidirectional fault current flow), is always challenging. Nevertheless, is not always possible to change meshed distribution networks to a radial conFigureuration for the protection purposes. As such, DOCRs are utilized for protecting distribution systems with mesh structure. There are some assumptions made prior to coming up with the scheme.

\subsection{Simplification Assumptions}

Due to the quite large solution space (possible combinations of DG placements and relay settings) and nature of the study, there are some assumptions made which include:-

$i$ - All DOCRs are identical and have the standard inverse relay curves.

ii- Single bus in the network can only take one DG unit.

iii- Constant load demands are used in the modelling instead of the time-varying demands. Such kind of demand do not contribute to any fault current.

$i v$ - Depending on the fault location, there can exist multiple backup DOCRs, but only one primary DOCRs. 
TSD and $I_{\mathrm{P}}$ settings are considered as the actual decision variables in finding the optimal relay settings of the proposed protection coordination technique. The TDS defines the operating time $\left(T_{\mathrm{OP}}\right)$ of the relay for each current value while the $I_{P}$ settings gives the minimum value of current for which the relay operates [16]. The relay time-current characteristic which shows the relationship between TSD and $I_{\mathrm{P}}$ can be expressed as:

$$
t_{i j}=T D S_{i} \frac{\lambda}{\left(\frac{I S C_{i j}}{{ }{ }_{P_{i}}}\right)^{\beta}-1}
$$

Where $t_{\mathrm{ij}}$ is the operating time of $i$ th relay at $j$ th fault location, $\lambda$ and $\beta$ are constants that vary with the type of OCR which are set to 0.14 and 0.02 . The term represents the relay short circuit current and represents the relay pickup current.

The study is carried out in two stages. In the first stage, TDS and $I_{\mathrm{P}}$ are optimally determined. While in the second stage, the maximum DG penetration level (PL) with changes in the protection coordination is evaluated. The outputs of the first stage are inputted to the second stage, as shown in Figure 1, in order to determine the maximum allowable DG PL considering protection coordination and relay operating time constraints. The DG PL is optimally computed at various CTI values.

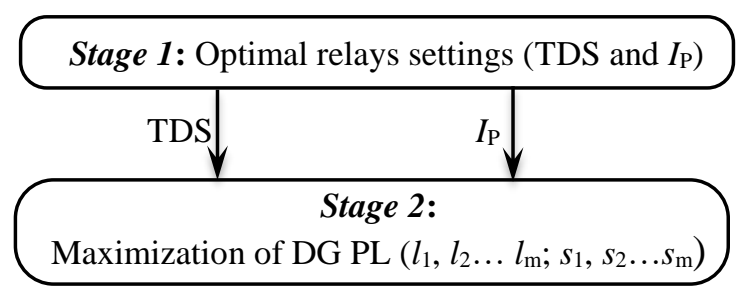

Figure 1. Schematics of the proposed scheme.

\subsection{Optimal Distribution Protection Coordination}

The relay protection coordination is formulated to minimize the $T_{\mathrm{OP}}$ formed by summing up the primary relay operating time and backup relay operating time, subject to some constraints.

$$
\text { minimize } T_{O P}=\sum_{i=1}^{N} \sum_{j=1}^{M}\left(t_{i j}^{p}+t_{i j}^{b}\right)
$$

Where: $N$ is the total number of relays, $M$ is the total number of fault locations, $t_{i j}^{p}$ is the primary relay $i^{\text {th }}$ operating time, $t_{i j}^{b}$ is the backup relay $i^{\text {th }}$ operating time for fault at location $j$. the minimization of the $T_{\mathrm{OP}}$ is carried out subject to some relay time constraints.

\subsubsection{Constraints of relay's settings}

The relay operating time is minimized subject to the upper and lower bound constraints on the relay's TDS and $I_{P}$ expressed as in (4):

$$
\begin{gathered}
I_{p i-\min } \leq I_{p i} \leq I_{p i-\max } \quad \forall_{i} \\
T D S_{i-\min } \leq T D S_{i} \leq T D S_{i-\max }, \forall_{i}
\end{gathered}
$$

$$
0 \leq t_{i j}^{p}, t_{i j}^{b} \leq t_{i j-\max }, \forall_{i, j}
$$

where $I_{p i-\min }$ and $I_{p i-\max }$ are the lower and upper limits on the relay pickup current setting, $T D S_{i-\min }$ and $T D S_{i-\max }$, are the lower and upper limits on the relay TDS setting which are set to 0.1 and 11 , respectively. The operating time are constrained to maximum relay operating time, $t_{i j-\max }$.

\subsubsection{Constraints of Coordination}

The aim of backup protection is to isolate the electric faults in case the primary protection fails, thus in order to avoid any interference between the primary and backup relays, it is necessary to set a time delay for backup activation. However, the CTI which is the time margin between primary and backup relays for a given fault, also depends on the delay of the primary relays, operating times of circuit breakers and instrument transformers. The minimum value of the CTI chosen for this work is chosen as 0.1sec just like Adhikari \& Kumar, (2015) and other reviewed literatures. The protection coordination is constrained as expressed in (7): -

$$
t_{i j}^{b}-t_{i j}^{p} \geq C T I_{i}
$$

\subsection{Maximization of DG Penetration Level}

The optimal values of the TDS and $I_{\mathrm{P}}$ obtained in the first stage are used as input constant parameters for the second stage. The main objective of the second stage is to maximize the DG PL with various values of the CTI. The objective function for this stage is formulated as:

where

$$
\max _{\left(l_{1}, l_{2}, \ldots, l_{m} ; s_{1}, s_{2}, \ldots, s_{m}\right)} f
$$

$$
f=\sum_{i=1}^{N}\left(P_{D G i}+j Q_{D G i}\right)
$$

$P_{\text {DGi }}(\mathrm{MW})$ and $Q_{\text {DGi }}(\mathrm{MVar}$ ) are the active and reactive power rating of DG unit at bus $i$ denoted as $s_{1}, s_{2} \ldots s_{m}$, while $l_{1}, l_{2} \ldots l_{\mathrm{m}}$, are the respective optimal locations. $N$ is the total number of DG units chosen to 3 synchronous based.

\subsubsection{Constraints for DG maximization}

The proposed DG maximization is carried out by considering the following constraints:-

1. Voltage limit: the bus voltage magnitudes are constrained within lower and upper limits as in (10),

$$
V_{j}^{\min } \leq V_{j} \leq V_{j}^{\max }, \quad j=1,2, \ldots, n_{b}
$$

2. Maximum permissible line current carrying capacity: to avoid exceeding the current capacity of the branches, the current in $k$ th branch, $I_{k}$ is limited to a maximum permissible current, $I_{k}^{\text {min }}$ as in (11),

$$
I_{k} \leq I_{k}^{\min }, \quad k=1,2, \ldots, n_{l}
$$


3. DG generation limits: Each DG unit is kept within its minimum and maximum power generation limits as expressed in (12) and (13),

$$
\begin{gathered}
P_{D G i}^{\min } \leq P_{D G i} \leq P_{D G i}^{\max } ; \quad \forall i \\
Q_{D G i}^{\min } \leq Q_{D G i} \leq Q_{D G i}^{\max } ; \quad \forall i
\end{gathered}
$$

Where $P_{D G i}^{\min }, P_{D G i}^{\max }, Q_{D G i}^{\min }$ and $Q_{D G i}^{\max }$ are the minimum and maximum active and reactive power generation limits of the DG units.

\section{TEST SYSTEM DESCRIPTION}

The proposed protection coordination scheme is implemented on the distribution section of the IEEE 14-bus and 30-bus systems and simulated in MATLAB.

\subsection{IEEE 14-bus system}

The first system considered in this work is distribution section of IEEE 14 system. The main system represents a simplified modification of the American Electric Power system having 14 buses, 5 generators, and 11 load points.

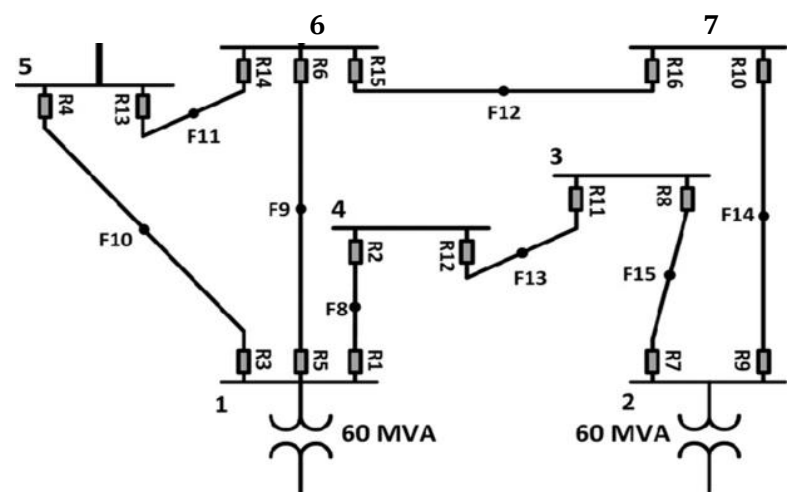

Figure 2. Distribution section of the IEEE 14-bus system

The distribution section of the system considered in this study has 7 buses, 8 fault locations denoted as F8 - F15, and is fed through two $60 \mathrm{MVA}, 132 \mathrm{kV} / 33 \mathrm{kV}$ transformers installed at buses 1 and 2 as shown in Figure 2. The system is equipped with 16 DOCRs denoted as R1 - R16, with two on either ends of the lines. The system line and bus data can be accessed in [17]. All the three DG units are connected to the system through a $480 \mathrm{~V} / 33 \mathrm{kV}$ distribution transformer with a transient reactance of $0.075 \mathrm{pu}$ at the optimal locations.

\subsection{IEEE 30-bus system}

The second system is distribution section of IEEE 30 system. The main system is a modification of the American Electric Power system having 30 buses, 6 generators, 4 transformers and 41 transmission lines. The distribution section of the system considered in this study has 14 buses, 16 fault locations denoted as $\mathrm{F} 15-\mathrm{F} 30$, and is fed through three $50 \mathrm{MVA}, 132 \mathrm{kV} / 33 k \mathrm{~V}$ transformers connected at buses 2,8 and 12 as depicted in Figure 3 . The system is equipped with 28 DOCRs denoted as $\mathrm{R} 1-\mathrm{R} 28$, with two on either ends of the lines. The system line and bus data can be accessed in [17].

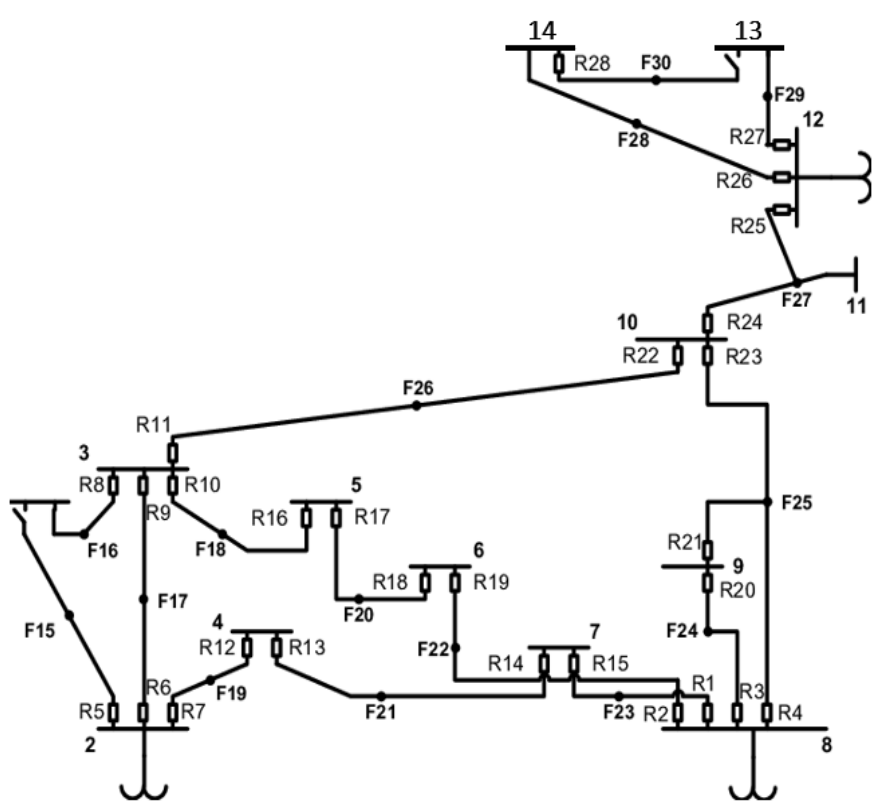

Figure 3. Distribution section of the IEEE 30-bus system

All the three DG units are connected to the system through a $480 \mathrm{~V} / 33 \mathrm{kV}$ distribution transformer with a transient reactance of $0.075 \mathrm{pu}$ at the optimal locations. In order to obtain the short circuit currents, a three-phase bolted fault at midpoint of each line fault is conducted with aid of Newton-Raphson power flow technique as well.

\section{SIMULATION RESULTS AND DISCUSSION}

In order to ascertain the effectiveness of the 2-stage scheme, it is implemented on the distribution section of the system described in the previous section.

\subsection{First Stage}

In this stage, optimal relays settings (TDS and $I_{P}$ ) are determined for each relay. All the DOCRs are assumed to be identical and have the standard inverse relay curves.

\subsubsection{IEEE 14-bus system}

By implementing the first stage on the distribution section of the IEEE 14-bus, the DOCRs' total operating time $T_{\mathrm{OP}}$ is minimized by determining the optimal relay settings using PSO. These settings, comprising of the DOCRs TDS and $I_{\mathrm{P}}$ are summarized in Table 1. The optimal solutions are compared with those obtained in [13]. 
Table 1. Comparison on Optimal Relay Settings for IEEE 14 System

\begin{tabular}{|c|c|c|c|c|}
\hline \multirow{2}{*}{$\begin{array}{c}\text { Relay } \\
\text { Number }\end{array}$} & \multicolumn{2}{|c|}{ Pickup Current $(\mathbf{p u})$} & \multicolumn{2}{c|}{ Time Dial Settings (sec) } \\
\cline { 2 - 5 } & $\begin{array}{c}\text { Adhikari \& } \\
\text { Kumar, 2015 }\end{array}$ & Developed & $\begin{array}{c}\text { Adhikari \& } \\
\text { Kumar, 2014 }\end{array}$ & Developed \\
\hline 1 & 0.9219 & 0.6638 & 0.0810 & 0.0551 \\
\hline 2 & 0.0815 & 0.0587 & 0.0644 & 0.0438 \\
\hline 3 & 0.0501 & 0.0361 & 0.0275 & 0.0187 \\
\hline 4 & 0.2558 & 0.1842 & 0.0132 & 0.0090 \\
\hline 5 & 0.2053 & 0.1478 & 0.0899 & 0.0611 \\
\hline 6 & 0.0500 & 0.0360 & 0.0812 & 0.0552 \\
\hline 7 & 0.9897 & 0.7126 & 0.0528 & 0.0359 \\
\hline 8 & 0.1241 & 0.0894 & 0.0188 & 0.0128 \\
\hline 9 & 1.2246 & 0.8817 & 0.0301 & 0.0205 \\
\hline 10 & 0.0593 & 0.0427 & 0.0686 & 0.0466 \\
\hline 11 & 0.0500 & 0.0360 & 0.0626 & 0.0426 \\
\hline 12 & 0.3024 & 0.2177 & 0.0868 & 0.0590 \\
\hline 13 & 0.3105 & 0.2236 & 0.0884 & 0.0601 \\
\hline 14 & 0.3957 & 0.2849 & 0.0182 & 0.0124 \\
\hline 15 & 0.3779 & 0.2721 & 0.0900 & 0.0612 \\
\hline 16 & 0.2980 & 0.2146 & 0.0125 & 0.0085 \\
\hline
\end{tabular}

As it can be seen from Table I, R9 has the highest pickup current of 1.2246pu from the work of Adhikari \& Kumar, (2015). With the application of the technique, it has been reduced to $0.8817 p u$. The relay serves as the primary relay for fault at bus 2 and backup for fault at bus 3. In contrast, R11 serving as the primary relay for fault at bus 3 has the minimum pickup current of $0.05 \mathrm{pu}$ and has been reduced to $0.0360 \mathrm{pu}$ as shown in Figure 4. Generally, pickup currents of the remaining relays have been reduced by $28 \%$ roughly.

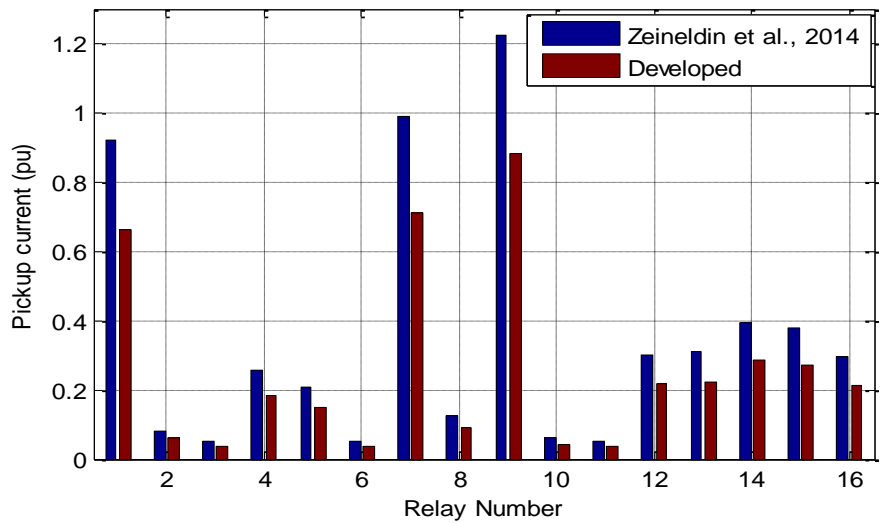

Figure 4. Pickup current for IEEE 14 bus system

Similarly, R15 has the maximum TDS of 0.09 sec from the work of [2]. With the application of the technique, it has been reduced to $0.0612 \mathrm{sec}$. The relay serves as the primary relay for fault at bus 6 and backup for fault at bus 5. In the same vain, R14 serving as the primary relay for fault at bus 6 has the minimum TDS of $0.0182 \mathrm{sec}$ and has been reduced to $0.0124 \mathrm{sec}$ as depicted in Figure 5. In general, the TDS of the remaining relays have been reduced by $32 \%$ approximately.
It is worth-noting that for fault at bus 2, relays R8 and R10 act as primary relays and R12, R15 act backups respectively. For fault at bus 4 relays R2, R12 acts as primary relays and R6, $\mathrm{R} 7$ act backup respectively.

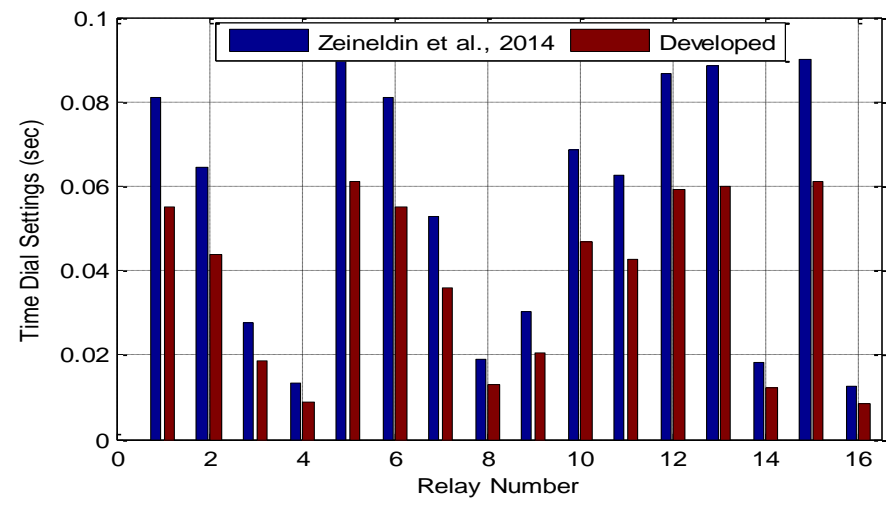

Figure 5. Time dial settings for IEEE 14 bus system

\subsubsection{IEEE 30-bus system}

By implementing the first stage on the distribution section of the IEEE 30-bus, the DOCRs' total operating time $T_{\mathrm{OP}}$ is minimized by determining the optimal relay settings using PSO. These settings, comprising of the DOCRs TDS and $I_{\mathrm{P}}$ are summarized in Table 2. The optimal solutions are compared with those obtained in [12].

Table 2. Comparison on Optimal Relay Settings for IEEE 30 System

\begin{tabular}{|c|c|c|c|c|}
\hline \multirow{2}{*}{$\begin{array}{c}\text { Relay } \\
\text { Number }\end{array}$} & \multicolumn{2}{|c|}{ Pickup Current (pu) } & \multicolumn{2}{c|}{ Time Dial Settings (sec) } \\
\cline { 2 - 5 } & $\begin{array}{c}\text { Zeineldin, } \\
\text { et al., 2014) }\end{array}$ & Developed & $\begin{array}{c}\text { (Zeineldin, } \\
\text { et al., 2014) }\end{array}$ & Developed \\
\hline 1 & 0.8320 & 0.6656 & 0.1000 & 0.0600 \\
\hline 2 & 0.6481 & 0.5185 & 0.1000 & 0.0700 \\
\hline 3 & 0.9675 & 0.7420 & 0.1000 & 0.0500 \\
\hline 4 & 0.1373 & 0.1098 & 0.1000 & 0.0800 \\
\hline 5 & 0.0767 & 0.0614 & 0.1000 & 0.0900 \\
\hline 6 & 0.6696 & 0.5117 & 0.1000 & 0.0510 \\
\hline 7 & 0.6990 & 0.5432 & 0.1000 & 0.0810 \\
\hline 8 & 0.0196 & 0.0157 & 0.1000 & 0.0710 \\
\hline 9 & 0.2485 & 0.1988 & 0.1000 & 0.0510 \\
\hline 10 & 0.5830 & 0.3064 & 0.1000 & 0.0810 \\
\hline 11 & 0.1938 & 0.1550 & 0.1000 & 0.0910 \\
\hline 12 & 0.2497 & 0.1998 & 0.1000 & 0.0710 \\
\hline 13 & 0.5174 & 0.4139 & 0.1000 & 0.0610 \\
\hline 14 & 0.4763 & 0.3810 & 0.1000 & 0.0741 \\
\hline 15 & 0.0684 & 0.0547 & 0.3102 & 0.2102 \\
\hline 16 & 0.0605 & 0.0484 & 0.2383 & 0.1638 \\
\hline 17 & 0.3713 & 0.2970 & 0.1000 & 0.0610 \\
\hline 18 & 0.4379 & 0.3503 & 0.1000 & 0.0910 \\
\hline 19 & 0.1828 & 0.1462 & 0.1000 & 0.0810 \\
\hline 20 & 0.0789 & 0.0631 & 0.2853 & 0.1500 \\
\hline 21 & 0.0166 & 0.0133 & 0.5786 & 0.4560 \\
\hline 22 & 0.1252 & 0.1002 & 0.1793 & 0.0793 \\
\hline 23 & 0.0627 & 0.0502 & 0.4036 & 0.3536 \\
\hline 24 & 0.1569 & 0.1255 & 0.1000 & 0.0510 \\
\hline & & & & \\
\hline
\end{tabular}




\begin{tabular}{|l|l|l|l|l|}
\hline 25 & 0.1788 & 0.1430 & 0.2670 & 0.1670 \\
\hline 26 & 0.2166 & 0.1733 & 0.1000 & 0.0810 \\
\hline 27 & 0.0622 & 0.0498 & 0.1000 & 0.0610 \\
\hline 28 & 0.0367 & 0.0294 & 0.1000 & 0.0710 \\
\hline
\end{tabular}

From Table 2, it can be observed that R3 has the highest pickup current of $0.9675 \mathrm{pu}$ from the work of Zeineldin, et al., (2015), [16]. With the application of the technique, it has been reduced to $0.7420 \mathrm{pu}$. The relay $\mathrm{R} 3$ acts as the primary relay for fault location F24 and serves as backup for fault location F25. While R8 serving as the primary relay for fault location F16 has the minimum pickup current of 0.0196pu and has been reduced to $0.0157 p u$ as shown in Figure 6. Generally, the pickup currents of the remaining relays have been reduced by $31 \%$ roughly.

Likewise, R20 has the maximum TDS of $0.5786 \mathrm{sec}$ from [16]. However, by applying the proposed PSO based coordination technique, the TDS of the R20 has been reduced to $0.456 \mathrm{sec}$. The relay serves as the primary relay for fault location F24 and backup for fault location F22 and F23. On the contrary, majority of the relays like R1 - R14, R17 - R19 and R26 - R28 have a minimum TDS of $0.1 \mathrm{sec}$ from [16]. This because the TDS of all the relays are constrained to have a TDS of at least $0.1 \mathrm{sec}$ in the study. So, majority of the relays pegged at that minimum allowable TDS. While in this proposed work, the TDS minimum constraint of all the relays are halved to $0.05 \mathrm{sec}$. It is therefore observed that all the TDS are reduced comparing the result of the proposed approach with that of [16] as shown in Figure 7.

Furthermore, the optimal primary operating times of all relays is depicted in Figure 8. It can be observed that the operating times are proportional to the TDS for each relay. This assertion can be confirmed by the study. However, the CTI which is the time margin between primary and backup relays for a given fault, also depends on the delay of the primary relays. From the operating times, CTIs can be computed. It can equally be observed that R23 with the highest operating times of $0.9548 \mathrm{sec}$ obtained in [16] has been reduced $0.7161 \mathrm{sec}$.

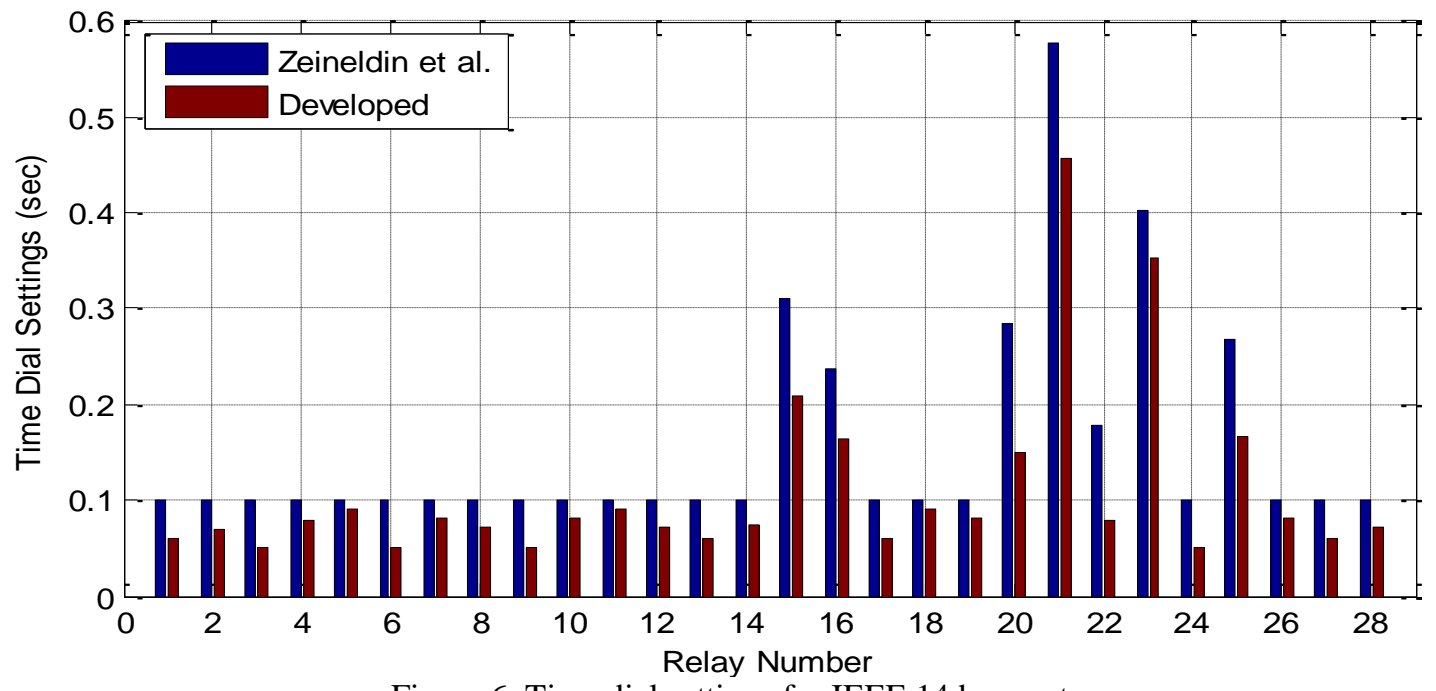

Figure 6. Time dial settings for IEEE 14 bus system

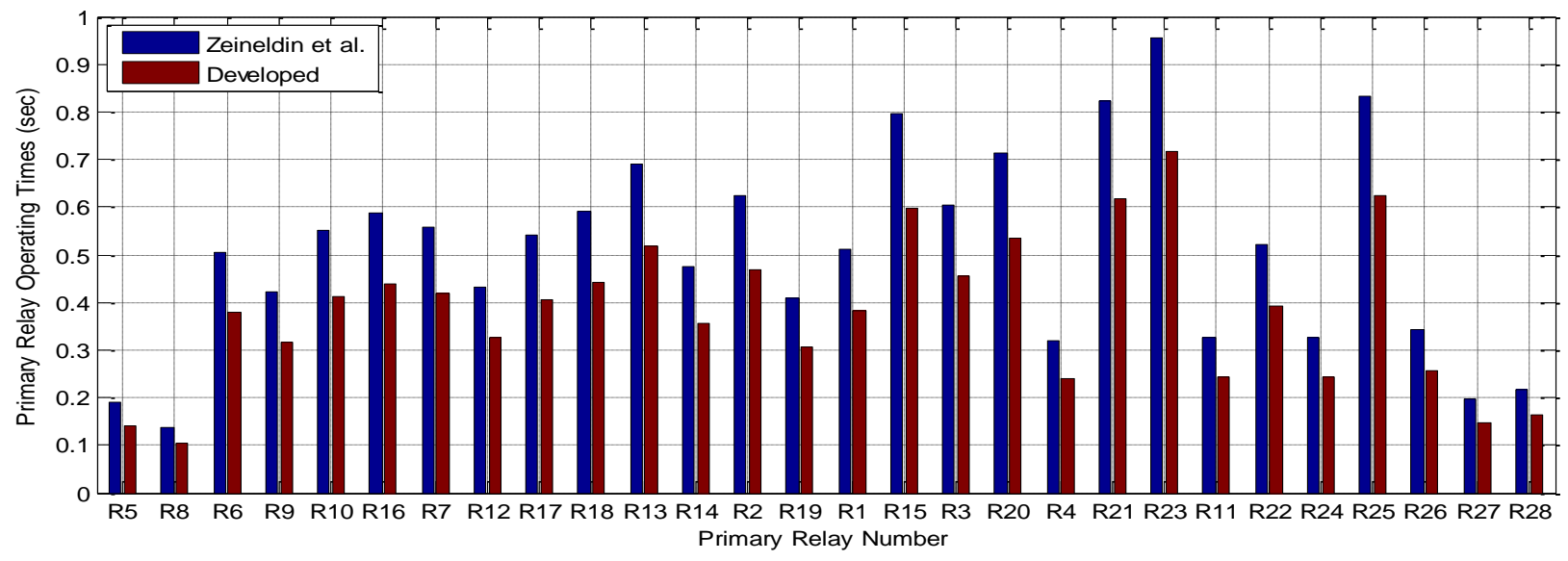

Figure 7. Developed Optimal Primary Relay Operating Times compared to Zeineldin, et al., (2015) 


\subsection{Second Stage}

In the second stage, the maximum DG penetration level with changes in the protection coordination is evaluated. The outputs of the first stage serve as input parameters to the second stage.

The optimal sizes and locations of the DG units in both test systems are summarized in Table 3 .

Table 3. Location and sizes of DG units

\begin{tabular}{|c|c|c|c|c|}
\hline $\begin{array}{c}\text { Test } \\
\text { System }\end{array}$ & DG & $\begin{array}{c}\text { Optimal } \\
\text { Locations }\end{array}$ & $\begin{array}{c}\text { Active } \\
\text { size } \\
\text { (MW) }\end{array}$ & $\begin{array}{c}\text { Reactive } \\
\text { size } \\
\text { (MVar) }\end{array}$ \\
\hline \multirow{2}{*}{ 14-bus } \\
system & 1 & Bus 5 & 8.695 & 5.2170 \\
\cline { 2 - 5 } & 2 & Bus 8 & 15.515 & 9.3090 \\
\cline { 2 - 5 } & 3 & Bus 12 & 16.334 & 9.8004 \\
\hline \multirow{2}{*}{ 30-bus } & 1 & Bus 19 & 13.9120 & 8.3472 \\
\cline { 2 - 5 } system & 2 & Bus 26 & 24.8240 & 14.8944 \\
\cline { 2 - 5 } & 3 & Bus 30 & 26.1344 & 15.6806 \\
\hline
\end{tabular}

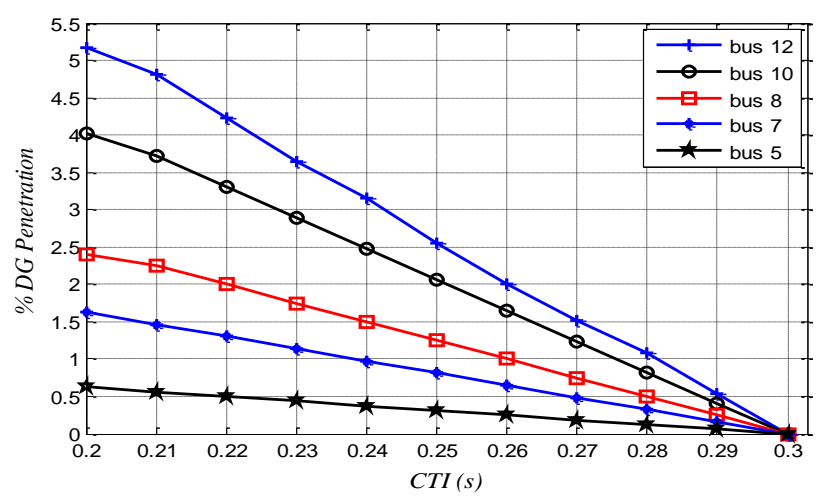

Figure 8. Variation of DG penetration with CTI for IEEE 14 bus system

The rate of the DG penetration level with respect to the CTI is analyzed. So, the DG penetration level is calculated for different values of CTI and the rate of change of the penetration level PL with respect to the rate of change of CTI is equally calculated. Thus, the $\%$ penetration level of the DG units placed at some selected locations is plotted against the CTIs as shown in Figure 9 and 10 for IEEE 14 and 30 systems respectively.

It can be seen that for IEEE 14 bus, the DG penetration per unit CTI is decreasing at bus 5 with the increase in capacity of installed DG connected at bus 10 . On the contrary, the DG penetration per unit CTI at bus 7 is increasing with the increase in the capacity of installed DG connected at bus 10 .

Similarly, it can be seen that for IEEE 30 bus, the DG penetration per unit CTI decreasing at bus 2 would decrease when 5MVA DG is installed. It can be seen that the impact on the protection coordination could be positive or negative. DG integration can have adverse effect on the protection coordination of the DOCRs.

\section{CONCLUSION}

In order to detect fault and isolate the selected faulty parts as quickly as possible to safeguard the system equipment, protective devices are put in place. Among the protective devices, over current protection relays is the widely used in power system at sub-transmission and distribution level. In this study, optimal distribution network protection coordination scheme with directional over current relays is developed. In addition, impact of optimally placed Distribution Generation (DG) on the protection coordination scheme is subsequently evaluated using relay Coordination Time Interval (CTI). Firstly, optimal relays settings (time dial settings and pickup current) are determined. Subsequently, the maximum DG penetration level with changes in the protection coordination is evaluated. Particle Swarm Optimization (PSO) algorithm, due to its faster convergence speed, is applied in both stages. The technique is implemented on the distribution section of the IEEE 14-bus and IEEE 30-bus systems and simulated in MATLAB. The simulation results obtained are compared with that obtained using hybrid Genetic Algorithm (GS) - Nonlinear Programming (NP) approach using relays pickup current and operating times as performance metrics. For the both test systems, there is significant improvement of the developed PSO-based relay coordination over the hybrid GA-NLP technique. It is envisioned as a future work to reconFigureure the network topology in order to increase the DG penetration level devoid of deteriorating the protection coordination scheme.

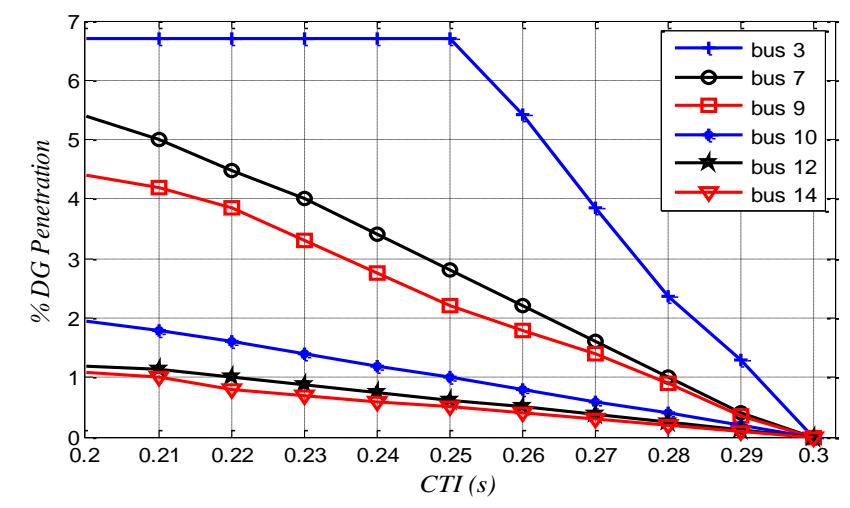

Figure 9. Variation of DG penetration with CTI for IEEE 14 bus system

\section{REFERENCES}

[1] Rathinam, A., Sattianadan D. \& Vijayakumar K., 2010. Optimal Coordination of Directional Overcurrent Relays using Particle Swarm Optimization Technique. International Journal of Computer Application, 10(2), pp. 43-47.

[2] Adhikari, A. \& Kumar, S., 2015. A Protection Coordination Index for Evaluating Distributed Generation Impacts on Protection for Meshed Distribution Systems Using Hybrid GA-NLP Approach. International Journal of Innovative Research and Development, 4(3), pp. $250-267$.

[3] Ahmadi, S. A., Karami, H. \& Gharehpetian, B., 2017. Comprehensive coordination of combined directional overcurrent and distance relays considering miscoordination reduction. International Journal of Electrical Power \& Energy Systems, vol. 92, pp. 42 52.

[4] Ali, A. F. \& A.Tawhid, M., 2017. A hybrid particle swarm optimization and genetic algorithm with population partitioning for large scale optimization problems. Ain Shams Engineering Journal, 8(2), pp. 191 $-206$.

[5] Castillo, C. A., Conde, A. \& E.Fernandez, 2018. Mitigation of DOCR mis-coordination through distance 
relays and non-standard overcurrent curves. Electric Power Systems Research, 163(A), pp. $242-251$.

[6] Castillo, C. A., Conde, A. \& Shih, M. Y., 2018. Improvement of non-standardized directional overcurrent relay coordination by invasive weed optimization. Electric Power Systems Research, Vol. 157 , pp. $48-58$.

[7] Darabi, A., Bagheri, M. \& Gharehpetian, G. B., 2020. Dual feasible direction-finding nonlinear programming combined with metaheuristic approaches for exact overcurrent relay coordination. International Journal of Electrical Power \& Energy Systems, vol. 114, pp. 1 14.

[8] Esteban, A., 2019. Coordination of distance and directional overcurrent relays using an extended continuous domain ACO algorithm and hybrid ACO algorithm. Electric Power Systems Research, vol. 170, pp. $259-272$.

[9] Moshtagh J., \& Ghasemi S., 2013. Optimal distribution system reconFigureuration using non-dominated sorting genetic algorithm (NSGA-II), Journal of Operation and Automation Power Engineering, vol. 1, pp. 12 - 21.

[10] Maleki, M. G., Chabanloo, R. M. \& Taheri, M. R., 2019. Mixed-integer linear programming method for coordination of overcurrent and distance relays incorporating overcurrent relays characteristic selection. International Journal of Electrical Power \& Energy Systems, vol. 110, pp. $246-257$.

[11] Mateus, C. H., Ravetti, M. G., Saldanha, R. R. \& Carrano, E. G., 2019. Minimizing undesirable load shedding through robust coordination of directional overcurrent relays. International Journal of Electrical Power \& Energy Systems, vol. 113, pp. 748 - 757.

[12] Nabab, M., Biswarup, A. \& Pant, D. V., 2015. A comparative study of metaheuristic optimization approaches for directional overcurrent relays coordination. Electric Power Systems Research, vol. 128 , pp. $39-52$.

[13] Nima, M., Mohammadi, R., Mahdi, C. \& Maleki, G., 2019. Optimal coordination of directional overcurrent relays considering two-level fault current due to the operation of remote side relay. Electric Power Systems Research, vol. 175, pp. $27-39$.

[14] Ojaghi, M. \& Mohammadi, V., 2018. Use of clustering to reduce the number of different setting groups for adaptive coordination of overcurrent relays. IEEE Transactions on Power Delivery, 33(3), pp. 1204 1212.

[15] Rathinam, A., D., S. \& K., V., 2010. Optimal Coordination of directional overcurrent relays using particle swarm optimization technique. International Journal of Computer Applications, 10(2), pp. 43 - 47.

[16] Zeineldin H. H., Abdel-Rady Y., Mohamed I., Khadkikar V., Ravikumar P. V., 2014. A Protection Coordination Index for Evaluating Distributed Generation Impacts on Protection for Meshed Distribution Systems. IEEE Transactions on Smart Grid, vol. 4, Issue: 3, pp. $1-1$ 